\title{
RELAÇÕES FAMILIARES DE MULHERES EM HEMODIÁLISE
}

\author{
FAMILY RELATIONSHIPS OF WOMEN ON HEMODIALYSIS
}

\section{Vanessa Athaydes Oliveiraa , Eda Schwartz ${ }^{\mathrm{b}}$, Marilu Correa Soares ${ }^{\mathrm{c}}$, Bianca Pozza dos Santos ${ }^{d}$, Raquel Pötter Garcia ${ }^{\mathrm{e}}$, Fernanda Lise ${ }^{\mathrm{f}}$}

avanessa-oliveir@live.com, beschwartz@terra.com.br, cenfmari@uol.com.br, dbi.santos@bol.com.br, eraquelpottergarcia@gmail.com, fernandalise@gmail.com Faculdade de Enfermagem da Universidade Federal de Pelotas - Pelotas (RS), Brasil

\section{RESUMO}

Introdução: A notícia de uma doença que torna a pessoa dependente de uma máquina, como é o caso da hemodiálise, pode gerar angústias e medo do desconhecido. A pessoa com a doença renal crônica depende de cuidados e a família caracteriza-se como elemento fundamental no processo de atendimento às necessidades do doente; entretanto, as emoçóes presentes nas relaçóes familiares podem ser consideradas negativas ou positivas, uma vez que a complexidade de cada família configura as diferenças e as congruências de cada pessoa. Objetivo: Conhecer as relaçóes familiares de mulheres em hemodiálise no contexto da doença renal crônica. Materiais e métodos: Estudo qualitativo, exploratório e descritivo, realizado em $2012 \mathrm{em}$ um serviço de nefrologia. Participaram seis mulheres em tratamento hemodialítico, que responderam a questôes abertas e fechadas e tiveram seus genogramas de família elaborados por um instrumento. Para a análise, foi realizada leitura exaustiva dos dados, codificaçôes e agregaçôes aos núcleos temáticos. Resultados: Os núcleos temáticos envolveram as relaçôes familiares negativas e positivas vivenciadas pelas mulheres em hemodiálise. Nas relaçôes familiares negativas, apareceram as dificuldades da família em prestar atenção, fornecer apoio e compreender as demandas de cuidados geradas pelo tratamento hemodialítico, havendo conflitos e abandono em alguns casos. Nas relaçóes familiares positivas, houve o amparo, a compreensão e o cuidado de acordo com as necessidades encontradas. Conclusóes: As relaçóes familiares negativas ou positivas das mulheres com doença renal em hemodiálise podem estar vinculadas às relaçóes interpessoais já existentes. Assim, conhecer as relaçóes familiares das mulheres em hemodiálise pode promover adequada intervençáo nos aspectos da vida familiar.

Palavras-chave: Insuficiência renal crônica; mulheres; família; enfermagem.

\section{ABSTRACT}

Introduction: The news of a disease that puts a person dependent on a machine, such as hemodialysis, may generate anguish and fear of the unknown. The person with chronic kidney disease depends of care, and the family is characterized as a fundamental element in the process of meeting the patient's needs; however, the emotions in family relationships can be considered positive or negative, since the complexity of each family sets the differences and consistencies of each person. Objective: To know the family relationships of women on hemodialysis in the context of chronic kidney disease. Materials and Methods: A qualitative, exploratory, and descriptive study, carried out in 2012 in a nephrology service. Participants were six women on hemodialysis who answered open and closed questions and had their family genogram constructed by an instrument. For the analysis, exhaustive reading of data, coding and aggregation to core themes was performed. Results: The core themes involved the negative and positive family relationships experienced by women on hemodialysis. In negative family relationships, difficulties in paying attention, offering support, and understanding the demands of care generated by hemodialysis were observed, with conflict and neglect in some cases. In positive family relationships, there was support, understanding and care according to the needs. Conclusions: Negative or positive family relationships of women with kidney disease on hemodialysis may be linked with existing interpersonal relationships. Thus, knowing the family relationships of women on hemodialysis can promote appropriate intervention in aspects of family life.

Keywords: Chronic renal insufficiency; women; family; nursing. 


\section{Introdução}

A notícia de uma doença que torna a pessoa dependente de uma máquina pode gerar muitas angústias e medo do desconhecido. A hemodiálise é tida como um dos tratamentos de substituição da função renal, que consiste na remoção dos líquidos e dos produtos do metabolismo do corpo, tornando-se necessária quando a pessoa encontra-se com a doença renal crônica (DRC) $)^{1-2}$.

A DRC é um problema de alta relevância, reconhecida como uma doença complexa que demanda múltiplas abordagens em seu tratamento, sendo que o mais utilizado no Brasil é a hemodiálise ${ }^{3}$. A pessoa que carrega os percalços de possuí-la pode se tornar vulnerável com as instabilidades decorrentes, pois possui obrigações, abnegaçóes e depende de cuidados, podendo se revoltar com seu tratamento ${ }^{4}$.

As mudanças na vida social, no trabalho, nos hábitos alimentares e na vida sexual da pessoa com DRC ocasionam alteraçóes em sua integridade física e psíquica. Ademais, a doença leva ao prejuízo corporal e limitaçóes, pois há o afastamento do convívio familiar. $\mathrm{O}$ indivíduo se sente ameaçado e inseguro, uma vez que ocorrem transformaçóes em seus valores, ideais e crenças em decorrência das mudanças orgânicas resultantes da doença renal, gerando consequências à qualidade de vida 5 .

Quando o indivíduo que se descobre com a DRC é uma mulher, sentimentos como medo, negação, ansiedade, irritação e incertezas quanto ao futuro e ao arranjo familiar surgem com mais intensidade. Logo, a inversão de papel vivenciada por ela provoca mudanças na rotina de sua família, pois muitas vezes a mesma passa de cuidadora principal à pessoa cuidada ${ }^{6}$.

Para as mulheres, as novas experiências ocasionadas pelo acometimento de uma doença renal crônica são intensas, podendo atingir toda a relação familiar ${ }^{2}$. A família caracteriza-se como elemento fundamental no auxílio ao cuidado da DRC, sendo necessário que os profissionais de saúde proporcionem subsídios para que os familiares possam dispensar um cuidado seguro ${ }^{7}$. Assim, é importante que os profissionais de saúde conheçam as percepçóes de mulheres com DRC em relação às limitaçóes enfrentadas com a doença, com o tratamento hemodialítico e os possíveis comprometimentos decorrentes dessas situaçóes, assim como as adaptaçóes necessárias em suas vidas para a concretização do cuidado ${ }^{8}$.

Nesse sentido, o enfermeiro, ao se aproximar da família para prestar o cuidado, pode compreender os significados e os sentimentos provindos das interaçóes entre seus membros. Isso possibilita indicar caminhos que favoreçam na diminuiçấo dos desgastes decorrentes da situaçáo de cronicidade e contribuir para a manutenção da integridade familiar ao planejar um cuidado fundamentado na estrutura das relaçóes familiares e na compreensáo dos sentimentos vivenciados diante da doença crônica?

$\mathrm{Na}$ realidade da DRC, a família enfrenta situaçóes desgastantes e conflitantes, causadoras de diversos sentimentos, tais como ansiedade, depressão, medo, raiva, tristeza, entre outros. Em virtude destes sentimentos, as relaçôes familiares podem ser abaladas, estabelecendo-se a desordem familiar. Entretanto, a presença de um doente crônico na família pode fortalecer os vínculos entre seus membros. Assim, a fragilidade ou a fortificação dos laços familiares serão influenciadas pelas condutas da família, havendo a capacidade de superar as dificuldades ou de deixar-se abalar por elas ${ }^{10}$.

Embora a hemodiálise seja utilizada no Brasil desde a década de 1950, constata-se um desconhecimento da população em geral tanto sobre a DRC quanto sobre o tratamento estabelecido. Dar voz às pessoas que vivenciam a doença, compreendendo seus anseios e necessidades, é importante para que a enfermagem e demais profissionais de saúde possam auxiliá-las a viver com qualidade de vida, apesar das limitaçóes impostas pela doença renal e pela própria terapêutica ${ }^{8}$. Nesse contexto, torna-se importante a produção de estudos que abordem a mulher em tratamento hemodialítico e a relação com o contexto familiar, principalmente pela inversão de papéis que pode ocorrer e as consequências para as relaçóes.

Assim, estudos sobre o conhecimento das experiências em família vivenciadas por mulheres em hemodiálise se constituem em importante produção científica no sentido de proporcionar e de dirigir as açóes dos profissionais de saúde e dos familiares cuidadores para uma atenção qualificada e humanizada às mulheres com DRC. Diante do exposto, este estudo tem por objetivo conhecer as relaçóes familiares de mulheres em hemodiálise no contexto da doença renal crônica.

\section{Metodologia}

Trata-se de um estudo qualitativo, exploratório e descritivo. A coleta de dados foi realizada nos meses de abril e maio de 2012 em um serviço de nefrologia de um hospital regional de grande porte, localizado na região Sul do estado do Rio Grande do Sul e no domić́lio das pessoas entrevistadas.

O estudo seguiu os princípios éticos da Resolução 196/96 do Conselho Nacional de Saúde do Ministério da Saúde, decorrente das diretrizes sobre pesquisa com seres humanos ${ }^{11}$. O projeto de pesquisa foi encaminhado ao Comitê de Ética em Pesquisa da Faculdade de Enfermagem da Universidade Federal de Pelotas, recebendo aprovação por meio do Parecer no 36/2012. Para manter o anonimato, as participantes foram 
identificadas pela letra $\mathrm{E}$, seguida do número arábico correspondente à ordem em que as entrevistas foram realizadas, acrescidos da idade.

O número de participantes foi seis mulheres em tratamento hemodialítico, que se encaixaram nos seguintes critérios de inclusão: período de realização da hemodiálise há pelo menos um ano; possuir idade igual ou superior a 18 anos; e ser capaz de se comunicar verbalmente e de forma clara.

As mulheres foram abordadas no serviço e convidadas a participar do estudo. Os objetivos, os riscos e os benefícios da pesquisa foram apresentados por meio do Termo de Consentimento Livre e Esclarecido (TCLE). Havendo concordância em participar do estudo, foi agendado local e horário em comum acordo para a realização das entrevistas.

No primeiro momento da entrevista, realizou-se a elaboração do genograma da família, que é um instrumento de avaliação da família, possibilitando representar a estrutura familiar interna por meio de gráficos convencionais genéticos e genealógicos ${ }^{12}$. Com a construção do genograma, é possível agregar informaçôes como os aspectos relacionais que denotam a estrutura e a configuração familiar, dando indícios de seu funcionamento e dinâmica ${ }^{13}$.

As entrevistas foram gravadas em mídia digital e, posteriormente, transcritas na íntegra. Os dados foram analisados conforme a proposta operativa de Minayo ${ }^{14}$, com leitura exaustiva dos dados, codificaçóes e agregaçóes aos núcleos de acordo com a operacionalização da análise temática, com a finalidade de encontrar os sentidos que compóem a comunicação, cuja frequência pode significar interpretaçóes para o estudo. Para concretizar a análise, seguiram-se as seguintes fases: pré-análise, exploração do material, tratamento dos resultados obtidos e interpretação.

\section{Resultados e discussão}

Para melhor compreensão dos resultados, primeiramente apresentam-se algumas características das mulheres entrevistadas e o genograma de suas famílias.

As características das mulheres entrevistadas podem ser visualizadas na Tabela 1:

Tabela 1: Descrição das características das mulheres entrevistadas no estudo.

\begin{tabular}{ccccc} 
Entrevistada & Estado civil & Filhos & Pessoas com quem reside & Tempo de hemodiálise \\
E1, 39 anos & Solteira & 01 & Sozinha & 1,5 ano \\
E2, 66 anos & Separada & 01 & Sozinha & 1 ano \\
E3, 49 anos & Casada & 03 & Esposo e três filhos & 20 anos \\
E4, 60 anos & Solteira & 00 & Sozinha & 4 anos \\
E5, 50 anos & Solteira & 00 & Mãe & 10 anos \\
E6, 43 anos & Casada & 04 & Esposo e dois filhos & 1 ano \\
\hline
\end{tabular}

Figura 1: Representação gráfica do genograma das famílias das entrevistadas.
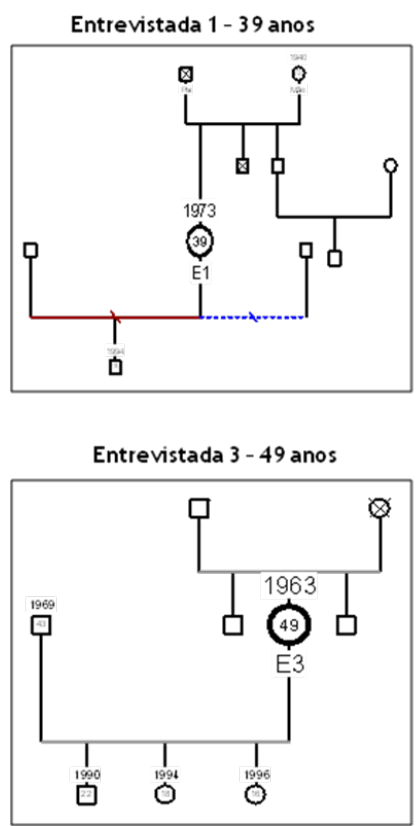
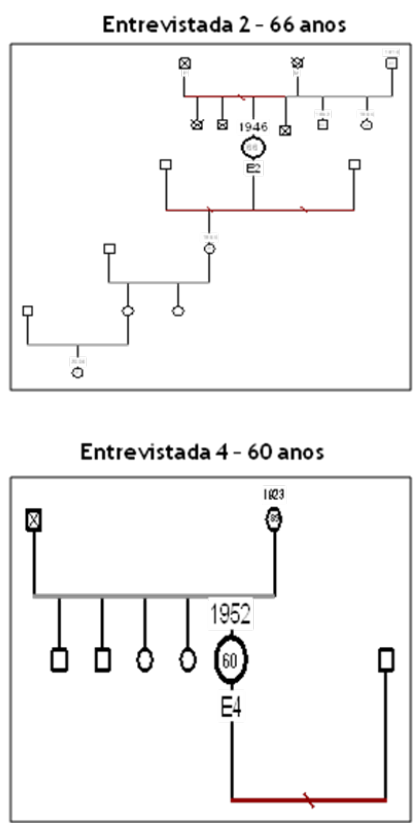
Entrevistada 5 - 50 anos

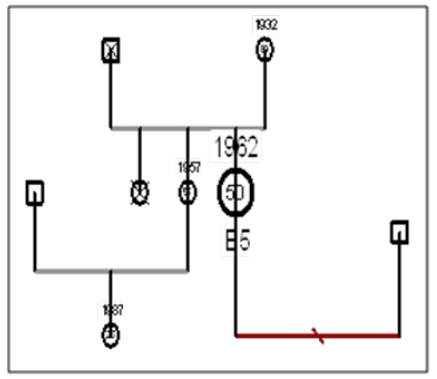

Entrevistada 6-43 anos

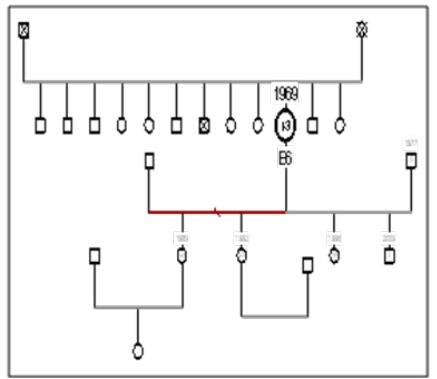

Homem

Mulher

\. Homem falecido

$\bigotimes$ Mulher falecida

(0) Mulher entrevistada

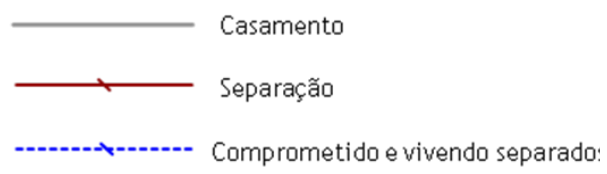

Fonte: Dados da pesquisa organizados no Software GenoPro, versão 2011.

A partir da análise dos dados coletados, emergiram os seguintes núcleos temáticos: "Relaçóes familiares negativas vivenciadas pelas mulheres em hemodiálise" e "Relaçóes familiares positivas vivenciadas pelas mulheres em hemodiálise”.

\section{Relações familiares negativas vivenciadas pelas mulheres em hemodiálise}

As mulheres entrevistadas, ao serem questionadas sobre sua relação com seus familiares, inicialmente referiram as dificuldades dos familiares para estarem presentes diante das demandas de cuidados geradas pelo tratamento hemodialítico. Expressaram tristeza com o descaso familiar em relação a sua doença e a terapêutica estabelecida.

Ele [esposo] tem uma charrete, então está sempre saindo, não para em casa e as gurias também e eu fico sozinha dentro de casa. Eles nem estão dando bola para nada, é difícil eles falarem assim, para mim, que eu tenho que tomar um remédio, se tem que isso, se tem que aquilo, eles nem estão dando bola para a minha doença (E3, 49 anos).

Tu sentes falta da tua familia, na hora que tu precisa, tu sentes falta, se separam. Tu estás boa, está tudo bem. Tu adoeces, todo mundo vai para um lado, não querem saber de compromisso [...]. Para eles, tanto faz se eu morrer ou não morrer, [...] não querem nem saber (E4, 60 anos).

Os depoimentos sugerem certa carência de cuidados por parte dos familiares das mulheres. Elas acreditam que devido à doença deveriam receber maior atençáo de seus familiares, e quando isso não ocorre, faz com que assumam uma posiçáo de inferioridade e se sentem solitárias. Nesse contexto, acredita-se que as relaçóes familiares diante da doença renal ficam prejudicadas, já que o doente quer receber atenção, talvez mais do que os familiares possam disponibilizar.

A doença pode afetar as relaçóes familiares e levar à fragmentaçấo da estrutura social, pois o processo de adoecer é desafiador nas relaçôes. Assim, é preciso atentar-se ao fato de que a família nem sempre está preparada para enfrentar a DRC em virtude da especificidade de cuidados a serem adotados ${ }^{15}$. Entretanto, ela também necessita ser cuidada e orientada para que tenha condiçôes de auxiliar o familiar com a doença renal ${ }^{7}$.

Entende-se que muitas vezes as dificuldades existentes em envolver a família no processo de atenção e de cuidado ao doente renal crônico podem estar implicadas à dificuldade de compreensão e de adaptação à nova realidade, pois cada indivíduo possui crenças sobre o que significa adoecer. Nessa lógica de pensamento, a orientação e o estímulo tornam-se necessários para que a participação da família no acompanhamento das demandas geradas pela doença e pelo tratamento possa ser feita com comprometimento e respeito, a fim de amenizar o sofrimento vivido pela mulher.

Como visto neste estudo, as mulheres necessitam lidar diariamente com os sentimentos de tristeza, apreensão e solidão que emergem do viver marcado pela DRC. A constante presença desses sentimentos leva a situaçóes conflitantes, provocando nos familiares um desgaste que prejudica ou dificulta o alcance do equilíbrio relacional, 
podendo afetar a atenção dispensada ao ente enfermo. Nesse sentido, o cuidado familiar deve alcançar dimensôes psicossociais que exceda às necessidades básicas de cuidado para a manutenção da saúde 9 .

Ainda na presença da DRC, são detectadas modificaçôes na vida das pessoas que geram tristeza, muitas vezes relacionadas ao distanciamento das relaçóes familiares mais próximas. Assim, com a presença da doença e da necessidade do tratamento hemodialítico, as pessoas acabam vivenciando relaçóes familiares e sociais prejudicadas. Muitas são abandonadas pela família, sendo comum também o afastamento dos amigos, repercutindo no isolamento social ${ }^{9,16}$. Esse fato pode ser exemplificado no depoimento a seguir: "Eles [familiares e amigos] nem vêm aqui na minha casa, moram aqui nos fundos $e$ nem vêm aqui, e eu vou estar forçando? Querem vir? Vêm. Não querem? Não venham. Quem tem que cuidar de mim, sou eu" (E4, 60 anos).

No depoimento da entrevistada E4, de 60 anos, emerge a solidão enfrentada pela mulher, principalmente pelo distanciamento dos familiares. Contudo, apesar da fragilidade relacional, ela parece seguir a vida dentro de suas possibilidades de cuidado.

Semelhante à fala apresentada acima, um estudo também constatou a manifestaçáo da tristeza pelos participantes ao perceberem a ocorrência de modificaçóes em suas vidas com o advento da doença crônica, lastimando a ausência e/ou deficiência nas relaçóes familiares e sociais, até mesmo com pessoas próximas?

Ainda como experiências negativas enfrentadas pelas mulheres, os relatos proporcionaram conhecer as relaçóes interpessoais com suas famílias, permitindo perceber que os conflitos familiares já existiam antes mesmo do estabelecimento da DRC e do tratamento hemodialítico.

Era um inferno a minha vida [...], só Deus sabe. [...] Até hoje que a gente não se dá direito. Nosso casamento foi um casamento assim, a gente só se viu e vocês vão casar [...]. Não é fácil. Olha, tem dias assim que eu digo, vou pegar o rumo e vou me sumir e ninguém vai me enxergar (E3, 49 anos).

A mãe mesmo não se dá comigo [...]. Já morei com ela e não deu certo. Ela que manda, xinga, tem que ser do jeito dela, tem que fazer o que ela manda [...]. Ela não quer nem que eu vá ali na minha cunhada, já andou me agredindo (E4, 60 anos).

Os depoimentos de E3, de 49 anos, e de E4, de 60 anos expressam características de família disfuncional, sendo que a existência de conflitos anteriores da DRC promove a incapacidade dos familiares cumprirem com a demanda de cuidados impostos pela doença. Talvez com a doença, os conflitos se tornem mais intensos pelas dificuldades relacionais que as famílias já vinham enfrentando.

O sistema familiar é complexo, dinâmico e influenciado pelo meio histórico, social e cultural. As relaçóes familiares, em alguma medida, interferem no processo de saúde e doença de seus membros, bem como na interpretaçáo da experiência de cada pessoa da família. Logo, a experiência advinda do adoecer ou durante a doença propriamente dita, reflete as experiências já vivenciadas e construídas ao longo da vida em família ${ }^{15}$.

Em vista dos dados encontrados nessa temática, percebe-se que, muitas vezes, as relações familiares negativas vivenciadas pelas mulheres com a DRC podem gerar isolamento social e emocional, principalmente se a família não possui conhecimento sobre a doença e a terapêutica adotada. Assim, ela também precisará ser orientada e cuidada.

\section{Relações familiares positivas vivenciadas pelas mulheres em hemodiálise}

Esta categoria expóe as relações familiares vivenciadas positivamente pelas mulheres em hemodiálise. Algumas relataram se sentir amparadas e compreendidas pela família diante da DRC e da hemodiálise.

Ela [mãe] está sempre do meu lado, ela me empurra sempre para fazer o que tem que fazer. Tipo assim, um remédio eu tomo bem nos primeiros dias e depois relaxo e ela está sempre em cima: "olha, tem que tomar o remédio" (E5, 50 anos).

$O$ apoio da familia numa hora dessas é a coisa mais importante que tem e todos me deram apoio [...]. A filha abandonou os estudos o ano passado para me acompanhar no tratamento [...]. Com a doença, podemos sentar, conversar, ver televisáo juntas, dar risadas, brincar (E6, 43 anos).

A partir dos relatos acima, percebe-se um movimento dos familiares para estar o mais presente possível na rotina das mulheres deste estudo após o surgimento da enfermidade. Esse apoio parece gerar bem-estar a elas, pois se sentem amparadas e seguras. Embora a DRC seja um problema que pode prejudicar as relaçóes, no contexto das famílias de E5, de 50 anos e de E6, de 43 anos, a doença teve papel de aproximação. Isso foi reforçado na fala de E6, de 43 anos, a mencionar que a filha abandonou os estudos para lhe acompanhar na hemodiálise, além de haver mais tempo para estarem próximas na realização de determinadas atividades.

As mudanças decorrentes do tratamento atingem os familiares que necessitam ajustar sua rotina diária às necessidades de apoio ao familiar que apresenta a DRC ${ }^{8}$. 
Destarte, o amparo da família diante da doença é importante para a continuidade e o enfrentamento do tratamento, uma vez que é no momento de crise que os laços familiares podem se fortalecer ${ }^{15}$. O suporte familiar é contundente na percepção das pessoas em relação à DRC e na manutenção do tratamento hemodialítico, e é decisivo para uma avaliação favorável sobre a qualidade de vida nesse contexto ${ }^{8}$.

Outro aspecto positivo nas experiências da família, segundo a compreensão de algumas das mulheres deste estudo, foi o cuidado prestado pela família.

Agora eu chego em casa, almoģo porque minha comadre já está com a comida, já deve estar pronta, aí eu me deito um pouquinho, sempre a gente cansa (E1, 39 anos).

A minha filha é incansável comigo, é muito boa, está sempre me ajudando, me levando comida, leva tudo que preciso comer e está sempre a minha volta, é muito boa mesmo. [...] Ela faz tudo por mim (E2, 66 anos).

Os depoimentos acima revelam cuidados, principalmente domésticos, que os familiares passam a desenvolver para as mulheres doentes, a fim de evitar possíveis complicaçóes. Assim, auxiliam na alimentação e em outras possíveis necessidades.

A família auxilia na promoção de arranjos, de mudanças e até altera os papéis para se adaptar à nova condiçâo. Quando a mulher pode contar com um familiar para conviver com o tratamento e a doença, esses eventos se tornam menos desgastantes, pois ela se sente segura por ter alguém com quem contar em momentos difíceis ${ }^{17}$.

Nesse sentido, estudos apontam que a família é um importante elo para o enfrentamento da doença e para adesão ao tratamento. Assim, torna-se essencial a sua inserção no cuidado à pessoa com DRC, para que ela possa sentir-se acolhida ${ }^{7,17}$.

Mesmo havendo adversidades na vida geradas pela DRC, as entrevistadas explanaram que as relaçóes entre os familiares podem ser permeadas por afeto e carinho. Ainda na fala da entrevistada E2, de 66 anos, há a preocupação de sua filha em prover meios, como a aquisição de um imóvel para que se sinta mais cuidada: "Minha filha achou que no apartamento eu estaria mais cuidada. Ela está pagando para mim, porque eu só ganho um salário" (E2, 66 anos).

Com esse depoimento, nota-se que os familiares também podem se organizar para ofertar melhor qualidade de vida à pessoa que está enfrentando o adoecimento. Dessa forma, buscam as mais variadas alternativas para que o bem-estar seja priorizado.

Ademais, no depoimento de E3, de 49 anos, observa-se que a instalação da doença promoveu a aproximação de outros familiares: "Ainda morei com minha sogra. Morei um monte de tempo com ela, eu doente e morava com ela lá. Ela me cuidava" (E3, 49 anos).

Os resultados encontrados nesta categoria mostram que algumas mulheres acometidas pela DRC conseguem obter relaçóes familiares positivas, decorrentes da vivência da doença e da realização da hemodiálise.

O reconhecimento e a valorizaçáo dos aspectos referidos pelas entrevistadas podem facilitar o processo de ampliação dos aspectos positivos e a diminuição dos aspectos negativos ou desgastantes ${ }^{8}$. Nesse sentido, a família tem papel fundamental no processo saúde/doença que está permeado por um conjunto de valores, crenças, conhecimento e práticas, os quais orientam as açóes dos membros da família na busca da promoção da saúde e do tratamento da doença ${ }^{18}$.

A existência de relações familiares positivas para a mulher com DRC em hemodiálise se torna importante. O apoio fornecido pela família diante do enfrentamento das mudanças ocorridas pela doença e pelo tratamento pode fazer com que se superem as dificuldades vivenciadas.

\section{Conclusão}

Os resultados apresentados proporcionaram conhecer as relaçóes familiares das mulheres com DRC em hemodiálise. As relaçóes familiares, independente de serem negativas ou positivas, podem estar vinculadas às relaçôes interpessoais já existentes. Acredita-se que se uma família vem enfrentando problemas nos relacionamentos, terá dificuldades em superar e auxiliar o integrante com DRC, que por sua vez acabará se sentindo sozinho e desamparado. Entretanto, se a família é unida, a presença da doença poderá estimular a união de seus membros, que reconhecerão a importância da participação e da presença de todos.

Os resultados deste estudo apontam que uma boa relação familiar e o apoio fornecido são importantes para que as mulheres consigam enfrentar a difícil jornada de tratamento e saibam lidar com a rotina e limitaçóes impostas pela DRC. Em contraposição, as mulheres que não possuíam harmonia na relação familiar relataram dificuldade em aceitar sua condição crônica.

Com base nesses achados, almeja-se que os profissionais da saúde fiquem atentos aos pacientes e aos familiares no decorrer do tratamento dialítico e da DRC, tendo em vista que essas pessoas podem estar com dificuldades no enfrentamento. Assim, conhecer as relaçóes familiares das mulheres em hemodiálise pode promover adequada intervenção nos aspectos da vida familiar, amenizando o sofrimento vivido. 


\section{Referências}

1. Daugirdas JT, Blake PG, Ing TS. Manual de diálise. $4^{\mathrm{a}}$ ed. Rio de Janeiro: Guanabara; 2010.

2. Oliveira VA. As experiências em família: a compreensão das mulheres em hemodiálise [dissertação]. Pelotas: Universidade Federal de Pelotas. Faculdade de Enfermagem, 2012.

3. Bastos MG, Kirsztajn GM. Doença renal crônica: importância do diagnóstico precoce, encaminhamento imediato e abordagem interdisciplinar estruturada para melhora do desfecho em pacientes ainda não submetidos à diálise. J bras nefrol. 2011;33(1):93-108.

4. Fortes VLF, Bettinelli LA, Pomatti DM, Brock J, Dobner T. Itinerário da doença renal crônica: do prenúncio à descoberta. Rev Rene. 2013;14(3):531-40.

5. Oliveira SG, Marques IR. Sentimentos do paciente portador de doença renal crônica sobre a autoimagem. Rev enferm Unisa. 2011;12(1):38-42.

6. Diogo HRSM. O cotidiano das mulheres em tratamento hemodialítico: potencialidades e limites [dissertação]. Pelotas: Universidade Federal de Pelotas. Faculdade de Enfermagem, 2010.

7. Barreto MS, Marcon SS. Doença renal crônica: vivências e expectativas do cuidador. Rev enferm UERJ. 2012;20(3):374-9.

8. Silva AS, Silveira RS, Fernandes GFM, Lunardi VL, Backes VMS. Percepçóes e mudanças na qualidade de vida de pacientes submetidos à hemodiálise. Rev bras enferm. 2011;64(5):839-44.

9. Caetano JPM, Fernandes MV, Marcon SS, Decesaro MN. Refletindo sobre as relaçóes familiais e os sentimentos aflorados no enfrentamento da doença crônica. Cienc cuid saude. 2011;10(4):845-52.

10. Feijó AM, Schwartz E, Jardim VMR, Linck CL, Zillmer JGV, Lange C. O papel da família sob a ótica da mulher acometida por câncer de mama. Cienc cuid saude. 2009;8:79-84.

11. Diretrizes e normas regulamentadoras de pesquisa envolvendo seres humanos. Resolução no 196, de 10 de outubro de 1996. Brasília: Conselho Nacional de Saúde; 1996.

12. Wright LM, Leahey M. Enfermeiras e famílias: guia para avaliação e intervenção na família. 5a ed. São Paulo: Roca; 2012.

13. Wendt NC, Crepaldi MA. A utilização do genograma como instrumento de coleta de dados na pesquisa qualitativa. Psicol reflex crit. 2008;21(2):302-10.

14. Minayo MCS. O desafio do conhecimento: pesquisa qualitativa em saúde. 13a ed. São Paulo: Hucitec; 2013.

15. Mattos M, Maruyama SA. A experiência em família de uma pessoa com diabetes mellitus em tratamento por hemodiálise. Rev eletr Enferm [periódico na Internet]. 2009 [acesso em 2014 Dez 23];11(4):971-81. Disponível em: http:// www.fen.ufg.br/revista/v11/n4/v11n4a23.htm

16. Prestes FC, Colomé CL, Tavares JP, Silva RM, Cordenuzzi OCP, Burg G, et al. Percepção dos trabalhadores de enfermagem sobre a dinâmica do trabalho e os pacientes em um serviço de hemodiálise. Texto contexto enferm. 2011;20(1):25-32.

17. Schwartz E, Muniz RM, Burille A, Zillmer JGV, Silva DA, Feijó AM, et al. As redes de apoio no enfrentamento da doença renal crônica. Rev min enferm. 2009;13(2):183-92.

18. Moreno V. Familiares de pacientes em hemodiálise convivendo com condiçóes crônicas de saúde. Rev Rene. 2008;9(4):40-56.

\section{Como citar este artigo:}

Oliveira VA, Schwartz E, Soares MC, Santos BP, Garcia RP, Lise F. Relaçóes familiares de mulheres em hemodiálise. Rev. Aten. Saúde. 2016;14(47): 36-42. 